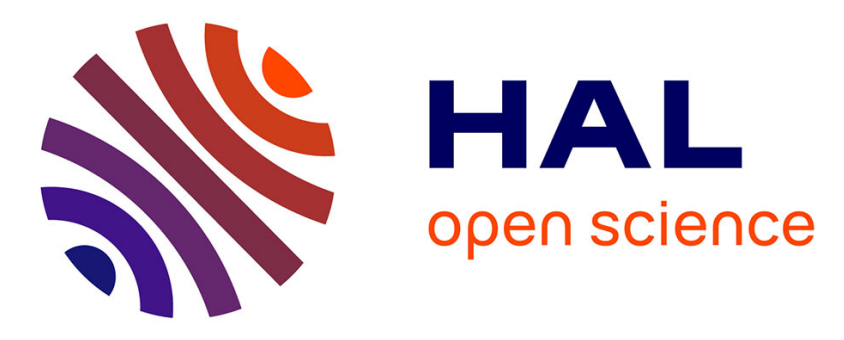

\title{
A two-dimensional screen for AMPK substrates identifies tumor suppressor fumarate hydratase as a preferential AMPK $\alpha 2$ substrate.
}

Anna Klaus, Cécile Polge, Sarah Zorman, Yolanda Auchli, René Brunisholz, Uwe Schlattner

\section{To cite this version:}

Anna Klaus, Cécile Polge, Sarah Zorman, Yolanda Auchli, René Brunisholz, et al.. A two-dimensional screen for AMPK substrates identifies tumor suppressor fumarate hydratase as a preferential AMPK $\alpha 2$ substrate.. Journal of Proteomics, 2012, 75 (11), pp.3304-13. 10.1016/j.jprot.2012.03.040 . inserm00696309

\section{HAL Id: inserm-00696309 https://www.hal.inserm.fr/inserm-00696309}

Submitted on 26 Sep 2017

HAL is a multi-disciplinary open access archive for the deposit and dissemination of scientific research documents, whether they are published or not. The documents may come from teaching and research institutions in France or abroad, or from public or private research centers.
L'archive ouverte pluridisciplinaire HAL, est destinée au dépôt et à la diffusion de documents scientifiques de niveau recherche, publiés ou non, émanant des établissements d'enseignement et de recherche français ou étrangers, des laboratoires publics ou privés. 


\title{
A two-dimensional screen for AMPK substrates identifies tumor suppressor fumarate hydratase as a preferential AMPK $\alpha 2$ substrate
}

\author{
Anna Klaus ${ }^{a, b, 1}$, Cécile Polge $e^{a, b, 1,2}$, Sarah Zorman ${ }^{a, b}$, Yolanda Auchlic, \\ René Brunisholz ${ }^{c}$, Uwe Schlattner ${ }^{a, b, *}$ \\ ${ }^{a}$ University Joseph Fourier, Laboratory of Fundamental and Applied Bioenergetics, Grenoble, France \\ bInserm, U1055, Grenoble, France \\ ${ }^{\mathrm{c}}$ Functional Genomics Center Zurich, ETH Zurich/University of Zurich, Switzerland
}

\section{A R T I C L E I N F O}

Article history:

Received 12 December 2011

Accepted 25 March 2012

Available online 3 April 2012

Keywords:

AMP-activated protein kinase

cell signaling

fumarate hydratase

protein kinase substrates

protein phosphorylation

surface plasmon resonance

\begin{abstract}
A B S T R A C T
AMP-activated protein kinase (AMPK) is emerging as a central cellular signaling hub involved in energy homeostasis and proliferation. The kinase is considered as a suitable target for pharmacological intervention in several energy-related pathologies like diabetes type II and cancer, although its signaling network is still incompletely understood. Here we apply an original two-dimensional in vitro screening approach for AMPK substrates that combines biophysical interaction based on surface plasmon resonance with in vitro phosphorylation. By enriching for proteins that interact with a specific AMPK isoform, we aimed to identify substrates that are also preferentially phosphorylated by this specific AMPK isoform. Application of this screen to full-length AMPK $\alpha 2 \beta 2 \gamma 1$ and soluble rat liver proteins identified the tumor suppressor fumarate hydratase (FH). FH was confirmed to interact with and to be preferentially phosphorylated by the AMPK $\alpha 2$ isoform by using yeast-two-hybrid and in vitro phosphorylation assays. AMPK-mediated phosphorylation of FH significantly increased enzyme activity in vitro and in vivo, suggesting that it is a bona fide AMPK substrate. In vivo, AMPK $\alpha 2$ is supposed to target the cytosolic/nuclear pools of FH, whose tumor suppressor function relies on DNA damage repair and inhibition of HIF-1 $\alpha$ signaling.
\end{abstract}

(c) 2012 Elsevier B.V. All rights reserved.

\section{Introduction}

AMP-activated protein kinase (AMPK) is member of a Ser/Thr kinase family conserved across the eukaryotic kingdom, including SNF1 complex in yeast and SnRK1 in plants. These kinases function as heterotrimeric complexes composed of one catalytic $\alpha$-type subunit and two regulatory $\beta$ - and $\gamma$-type subunits [1-4]. Subunits of mammalian AMPK occur as different isoforms $(\alpha 1$, $\alpha 2, \beta 1, \beta 2, \gamma 1-3$ ) and splice variants (of $\gamma 2$ and 3), potentially generating multiple different heterotrimeric complexes.

In mammals, AMPK functions mainly as an energy sensor, integrating signals from inside the cell, the cellular

\footnotetext{
* Corresponding author at: Uwe Schlattner, Inserm, U1055, Laboratory of Fundamental and Applied Bioenergetics, University Joseph Fourier, BP 53, F-38041 Grenoble Cedex 9, France. Tel.: +33 4765146 71; fax: +33 476514218.

E-mail address: uwe.schlattner@ujf-grenoble.fr (U. Schlattner).

1 These authors contributed equally to this work.

2 Present address: INRA, UMR 1019, UNH, CRNH Auvergne and Université d'Auvergne, Unité de Nutrition Humaine, BP 10448, F-63000 Clermont-Ferrand, France.
} 
environment, and the whole organism (for reviews see [5-8]). The activation mechanism involves AMP-induced conformational changes, covalent activation by the upstream kinases LKB1 or CamKK $\beta[9,10]$, and AMP- and ADP-dependent inhibition of AMPK dephosphorylation. Altered AMPK signaling has been associated with different human pathologies like diabetes and cancer, and the kinase is a promising drug target for these pathologies [11,12]. Two of the major drugs used for treating diabetes type II, metformin and thiazolidinediones, activate AMPK $[13,14]$ and many of their therapeutic effects are mediated by AMPK signaling [15]. The identification of LKB1, a known tumor suppressor, as an upstream kinase of AMPK [10] and the effect of metformin reducing cancer incidence [16] have generated substantial interest for the role of AMPK in cancer development. Activated AMPK negatively regulates cell proliferation and the cell cycle, mostly mediated by mTOR and p53, respectively [17-19]. However, treatments based on a systemic activation of AMPK may not only be beneficial, given the largely pleiotropic effects to be expected from a growing number of AMPK substrates.

Systemic activation may be avoided to some degree by targeting specific AMPK isoform combinations, since they show a partial tissue-specificity [20] or may recognize specific substrates. However, information on putative determinants of kinase-substrate interaction is scarce. Few AMPK interactors have been independently verified by more than one method [21-23], and most interaction data come from large-scale screening like immunoprecipitation-MS analysis with tagged AMPK [24], which do even not proof direct interactions. The variable $\mathrm{N}$-terminal region of the $\beta$-subunits has been proposed to mediate interaction of the kinase with its substrates in yeast [25] and plants [26]. In mammals, the $\alpha 1$ and $\alpha 2$ subunits were shown to exhibit subtle different substrate preferences when using variants of the SAMS peptide, suggesting that the two $\alpha$ isoforms could phosphorylate different substrates within the cell [27], but this could not be confirmed so far for known AMPK substrates.

To identify substrates that interact with a specific AMPK isoform combination and thus potentially represent preferential substrates of this AMPK species, we have set up a protocol involving prefractionation and a two-dimensional in vitro screening. This combines biophysical interaction assays using surface plasmon resonance (SPR) with in vitro phosphorylation assays and protein identification by mass spectrometry (MS) as successfully applied already in an earlier study [28]. This approach identified the tumor suppressor fumarate hydratase (FH) as an interactor and preferential substrate of $\alpha 2$-containing AMPK complexes, with phosphorylation leading to enzymatic activation.

\section{Material and methods}

\subsection{Material}

AICA-Riboside (AICAR) was from Biotrend Chemicals (Zurich, Switzerland), rabbit polyclonal anti-P-Thr172 AMPK $\alpha$ and antiHis-tag antibodies from Cell Signaling Technology (Danvers, MA, USA), goat polyclonal anti-GSTpi and rabbit polyclonal anti-FH antibody from Abcam (Cambridge, UK), secondary antibodies coupled to horseradish peroxidase were from GE Healthcare Life Science (Buckinghamshire, UK) for rabbit IgG and Thermo Scientific (Rockford, USA) for goat IgG.

\subsection{Cloning and purification of proteins}

Plasmids p $\gamma 1 \beta 1$ His- $\alpha 1$, p $\gamma 1 \beta 1$ His- $\alpha 1$ T172D, p $\gamma 1 \beta 2 H i s-\alpha 2$ and p $\gamma 1 \beta 1$ His- $\alpha 2$ T172D [29] were used for bacterial expression and purification as published previously $[29,30]$. For $\mathrm{Y} 2 \mathrm{H}$ experiments, PCR-amplified inserts were introduced into $\mathrm{Y} 2 \mathrm{H}$ vectors $\mathrm{pCab}$ and pDSL (Dualsystems Biotech AG, Schlieren, Switzerland). FH (mature form lacking signal peptide, GeneID: 24368) and fatty acid binding protein 1 (FABP1, GeneID: 24360) were amplified from rat liver CDNA and introduced into yeast two-hybrid vectors or bacterial expression vectors pET-52b (+) (Merck KGaA, Darmstadt, Germany) and pGEX-4 T-1 (GE Healthcare). The fusion constructs Strep-FH, Strep-FABP1, GST-FH, GST-FABP1, GST-ACC (plasmid kindly provided by G. Hardie, Univ. of Dundee, UK) [31] and GST-CamKK $\beta$ (plasmid kindly provided by H. Tokumitsu, Kagawa Medical University, Japan) were bacterially expressed and purified according to standard procedures and the tag proteolytically removed where necessary. For further details see the online Supplementary Material 1.

\subsection{Preparation and prefractionation of liver extract}

Total liver from one rat was snap-frozen in liquid nitrogen and homogenized in $15 \mathrm{ml}$ ice-cold extraction buffer A $(20 \mathrm{mM}$ HEPES, pH 7.4, $100 \mathrm{mM} \mathrm{NaCl}, 50 \mu \mathrm{M}$ EDTA, and anti-protease cocktail, 1 tablet per $50 \mathrm{ml}$ solution, Roche Diagnostics, Basel, Switzerland) using a Polytron PT 3000 homogenizer at $24000 \mathrm{rpm}$ for $20 \mathrm{~s}$. After centrifugation at $15000 \mathrm{~g}$ for $30 \mathrm{~min}$ at $4{ }^{\circ} \mathrm{C}$, the supernatant was filtered through a $0.22 \mu \mathrm{m}$ filter. Prefractionation was carried out on an Äkta Explorer 100 Air HPLC system (GE Healthcare). Three $\mathrm{ml}$ of liver extract were applied to a Ni-NTA column ( $2 \mathrm{ml}$ bed volume; Qiagen) preequilibrated in buffer $\mathrm{A}$. The column was then washed at a flow rate of $1 \mathrm{ml} / \mathrm{min}$ with 2 column volumes (CV) of buffer A. Proteins were eluted with imidazole buffer (20 mM HEPES, $\mathrm{pH}$ 7.4, $100 \mathrm{mM} \mathrm{NaCl}$ and $250 \mathrm{mM}$ imidazole) and the first $5 \mathrm{ml}$ collected. This process was repeated 3 times. Between each load, the column was washed with $4 \mathrm{CV}$ imidazole buffer, $1 \mathrm{CV}$ water, $1 \mathrm{CV} \mathrm{NaOH} 0.5 \mathrm{M}$ and $5 \mathrm{CV}$ buffer A. To reduce the volume, collected proteins were precipitated with $80 \%(\mathrm{w} / \mathrm{v})$ ammonium sulfate for 2 hours at $4{ }^{\circ} \mathrm{C}$. The pellet was resuspended in $5 \mathrm{ml}$ buffer $\mathrm{A}$ and further centrifuged at $15000 \mathrm{~g}$ for $10 \mathrm{~min}$ at $4{ }^{\circ} \mathrm{C}$. The supernatant was filtered $(0.22 \mathrm{~mm}$ filter) and applied to a Superdex 200 size exclusion column (separation range $\mathrm{Mr} 10$ 000-600 000; volume $120 \mathrm{ml}$; GE Healthcare) preequilibrated in buffer A. Proteins were then separated at a flow rate of $1 \mathrm{ml} / \mathrm{min}$ and collected in 12 fractions of $5 \mathrm{ml}$ each (S1 to S12) supplemented with anti-protease cocktail (Roche, 1 tablet per $50 \mathrm{ml}$ solution) was added.

\subsection{Surface plasmon resonance interaction screening and yeast two-hybrid assays}

The SPR screening was performed with a BIAcore 2000 (GE Healthcare) using a NTA sensor chip (GE Healthcare) and as running buffer $10 \mathrm{mM}$ HEPES $\mathrm{pH}$ 7.4, $100 \mathrm{mM} \mathrm{NaCl}, 50 \mu \mathrm{M}$ 
EDTA and 0.005\% Surfactant P20. In each measurement cycle, the NTA surface was activated by a 1 min-pulse of $500 \mu \mathrm{M}$ $\mathrm{NiCl}_{2}$ and $50 \mathrm{nM}$ His-tagged AMPK $\alpha 2 \beta 2 \gamma 1$ (AMPK221) was injected at $5 \mu \mathrm{l} / \mathrm{min}$ until reaching 4000 response units (RU) of immobilization. An HPLC fraction was then injected onto the AMP221 surface at $20 \mu \mathrm{l} / \mathrm{min}$ for $120 \mathrm{~s}$. Interacting protein was quantified at a reporting point $80 \mathrm{~s}$ after dissociation start, since the association phase was biased by an SPR signal caused by the chromatography sample buffer. After $120 \mathrm{~s}$ of dissociation, a protein-free surface was regenerated by injection of $10 \mathrm{mM}$ HEPES, pH 8.3, $150 \mathrm{mM} \mathrm{NaCl}, 350 \mathrm{mM}$ EDTA and 0.005\% Surfactant P20. Binary protein-protein interactions were analyzed in vivo using the Cyto-Y2H system (Dualsystems Biotech) [32] based on the split-ubiquitin system $[33,34]$ (see online Supplementary Material 1).

\subsection{Co-immunoprecipitation}

Strep-tagged FH ( $1 \mu \mathrm{g})$ and His-tagged AMPK 221TD $(1 \mu \mathrm{g})$ were co-immunoprecipitated with anti-His-tag antibody (1:200) and protein G Sepharose (10\% w/v) in IP buffer (30 mM Hepes $\mathrm{pH}$ 7.3, $300 \mathrm{mM} \mathrm{NaCl}, 6 \mathrm{~g} / \mathrm{l} \mathrm{BSA}, 0.5 \% \mathrm{w} / \mathrm{v}$ dodecylmaltoside) overnight at $4{ }^{\circ} \mathrm{C}$. Sepharose was washed twice $(30 \mathrm{mM}$ Hepes pH 7.3, $300 \mathrm{mM} \mathrm{NaCl}, 0.1 \%$ Tween 20) and resuspended in SDS-PAGE sample buffer. Proteins separated by SDS-PAGE were probed for $\mathrm{FH}$ by immunoblotting.

\subsection{AMPK substrate phosphorylation screening}

AMPK phosphorylation assays were performed at $37^{\circ} \mathrm{C}$ in a final volume of $25 \mu \mathrm{l}$ containing $12.5 \mu \mathrm{l}$ of chromatography fractions and kinase buffer $\left(200 \mu \mathrm{M}\left[\gamma^{-32} \mathrm{P}\right] \mathrm{ATP}(400 \mathrm{mCi} /\right.$ mmol ATP), $50 \mu \mathrm{M}$ AMP, $5 \mathrm{mM} \mathrm{MgCl2,} 1 \mathrm{mM}$ DTT and $10 \mathrm{mM}$ HEPES $\mathrm{pH}$ 7.4), with or without recombinant constitutively active AMPK221 (50 pmol). The kinase reactions were stopped after 2 min by addition of $10 \mu \mathrm{l}$ SDS sample buffer (105 mM Tris-HCl, pH 6.8, 4\% (w/v) SDS, 15\% (v/v) glycerol, $1.2 \mathrm{M} \beta$-mercaptoethanol, and $0.02 \%(\mathrm{w} / \mathrm{v})$ bromophenol blue), heated to $95^{\circ} \mathrm{C}$ for $5 \mathrm{~min}$, and separated by SDSPAGE. Following colloidal Coomassie staining, gels were airdried and exposed to autoradiography films (GE Healthcare) for up to 2 weeks or to Typhoon imager (GE Healthcare).

\subsection{Trypsin digestion and mass spectrometry}

Radioactively labeled AMPK-specific bands were cut from the gels, in-gel trypsin-digested (Promega), and extracted peptides analyzed by MALDI MS and MALDI MS/MS using an Ultraflex TOF/TOF II (Bruker Daltonics, Bremen, Germany). Processed spectra were combined through BioTools software (Bruker Daltonics) to search the Uniref100 database (release 6.0), non restricted to the taxonomy, using MASCOT software v. 2.0 (Matrix Science, London, UK). Probability-based MOWSE scores greater than 50 were considered significant. For details see the online Supplementary Material 2.

\subsection{In vitro analysis of AMPK substrate phosphorylation}

To compare phosphorylation kinetics, purified FABP1, FH and ACC Strep- or GST-constructs $(200$ pmol) were incubated for 5 ,
10, 20, 30 and $60 \mathrm{~min}$ at $37{ }^{\circ} \mathrm{C}$ with $200 \mu \mathrm{M}\left[\gamma^{-32} \mathrm{P}\right] \mathrm{ATP}$ (specific activity $650 \mathrm{mCi} / \mathrm{mmol} \mathrm{ATP}$ ) and AMPK221 (4 pmol) previously activated by incubation with 1 pmol CamKK $\beta$ for $20 \mathrm{~min}$ at $30{ }^{\circ} \mathrm{C}$ in kinase buffer (200 $\mu \mathrm{M}$ ATP, $50 \mu \mathrm{M}$ AMP, $5 \mathrm{mM} \mathrm{MgCl}_{2}$, $1 \mathrm{mM}$ DTT, $10 \mathrm{mM}$ HEPES pH 7.4). To compare phosphorylation by different AMPK isoforms, purified Strep-FH and GSTACC $(200 \mathrm{pmol})$ were incubated for $8 \mathrm{~min}$ at $37^{\circ} \mathrm{C}$ in the presence or absence of 3 pmol previously activated AMPK (AMPK221, -211 or -111) in kinase buffer containing $200 \mu \mathrm{M}$ $\left[\gamma^{-32} \mathrm{P}\right]$ ATP (specific activity $650 \mathrm{mCi} / \mathrm{m} \mathrm{mol} \mathrm{ATP)}$. For negative controls, AMPK substrates were incubated with $1 \mathrm{pmol}$ CamKK $\beta$ alone without AMPK. Kinase reactions were stopped by addition of SDS-PAGE sample buffer and subjected to SDSPAGE and Typhoon phosphoimager (GE Healthcare).

\subsection{AMPK activation in cell culture}

HeLa cells were cultured in DMEM/F12 high glucose medium supplemented with $10 \%$ inactivated fetal calf serum (FCS) and 1\% glutamate/streptomycine/penicillin. Endogenous AMPK of HeLa cells was activated by treatment with $1 \mathrm{mM}$ AICAR for $1 \mathrm{~h}$ at $37^{\circ} \mathrm{C}$. Cells were then trypsinated, collected by centrifugation (1200 g, $5 \mathrm{~min}$ ), and resuspended in lysis buffer (50 mM Tris/HCl pH 7.5, 100 mM NaCl, $5 \mathrm{mM} \mathrm{MgCl}_{2}, 1 \% \mathrm{NP}-40$, $0.1 \%$ SDS) supplemented with protease (Roche) and phosphatase (Thermo Scientific) inhibitor cocktail. Cells were lysed by sonication and insoluble material was removed by centrifugation (10 min, $10000 \mathrm{~g}, 4^{\circ} \mathrm{C}$ ). AMPK activation was verified by immunoblotting using anti P-Thr172 AMPK $\alpha$ antibody. Immunoblot against GSTpi was used as a loading control.

\subsection{Fumarate hydratase enzyme activity}

AMPK221 was activated by CamKK $\beta$ and incubated with GST-FH in kinase buffer for $30 \mathrm{~min}$ at $37^{\circ} \mathrm{C}$ prior to activity measurements. Enzyme activity of $\mathrm{FH}$ and phospho-FH was then determined at $25^{\circ} \mathrm{C}$ by a spectrophotometric assay measuring fumarate formation $(240 \mathrm{~nm})$ in $0.1 \mathrm{M}$ potassium phosphate buffer $\mathrm{pH} 7.6$ using 0.5 to $8 \mathrm{mM}$ malate. Data were analyzed by direct fitting to Michaelis-Menten kinetics and secondary plots using SigmaPlot 10 (Systat Software, USA). FH activity of HeLa extracts was measured under the same conditions using $2.5 \mathrm{mM}$ malate.

\section{Results}

\subsection{Setup of an in vitro AMPK substrate screen}

With the rationale to use the affinity between the kinase and its substrates as an additional parameter in a two-dimensional screening matrix for new substrates, we set out the following strategy (Fig. 1): Starting with soluble proteins within a cell extract of rat liver, we (i) eliminated proteins that nonspecifically interact with Ni-NTA matrix, (ii) reduced complexity via size exclusion chromatography, (iii) screened for fractions containing AMPK interactors by using Biacore SPR with Histagged AMPK221 immobilized on an NTA sensor chip, and finally (iv) screened SPR-positive fractions with in vitro phosphorylation assays using constitutively active AMPK221. 


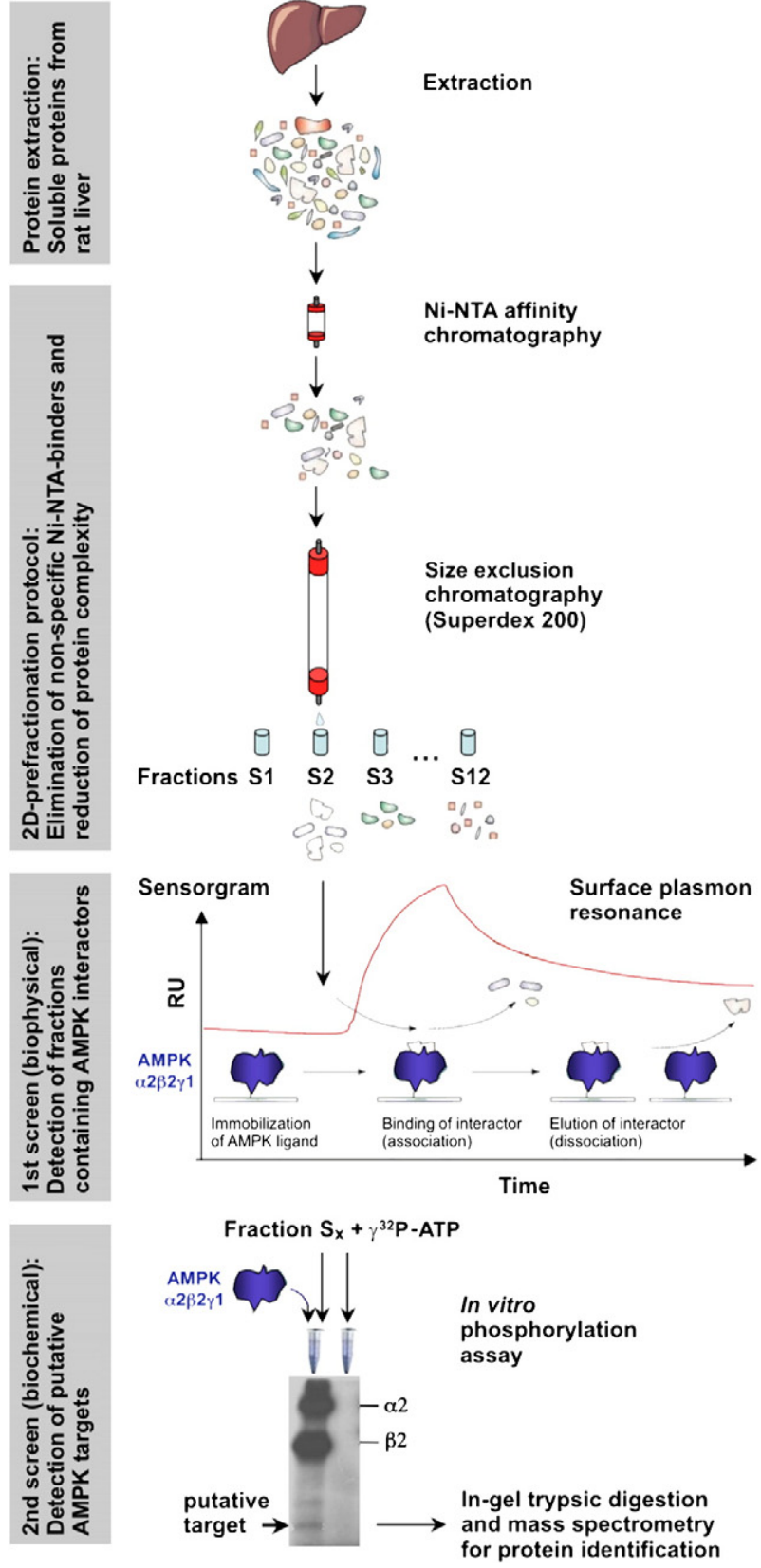

Fig. 1 - Flow chart of the in vitro screening procedure. A tissue-derived extract containing soluble proteins is pre-fractionated by two step column chromatography with different sorbent chemistries. Each fraction is then analyzed by SPR for the presence of AMPK221 interacting proteins. Positive fractions are subjected to in vitro phosphorylation assays for detection of potential downstream substrates. After SDS-PAGE separation and autoradiography, positive lanes are excised and proteins identified by mass spectrometry.

Preliminary experiments had revealed a high degree of non-specific protein binding to the NTA surface during SPR (not shown), which could be eliminated by an initial NiNTA chromatography step. Prefractionation with size exclusion chromatography on a Superdex 200 column had the additional advantage that eluted fractions contained proteins of similar size. This is an important prerequisite for the subsequent SPR experiments, since the SPR signal directly correlates with the mass bound at the chip surface, and thus not only with the number but also with the size of the bound protein. The unprocessed protein chromatography fractions were individually analyzed by Biacore SPR on surfaces covered with AMPK221 or left blank (Fig. 2). Fractions were considered interaction-positive when $80 \mathrm{~s}$ after dissociation start the SPR response on the AMPK221 surface was still higher as compared to the blank surface (fractions S1, S2, S3, S4, S10, S11 and S12). Fraction S1 contained mainly aggregates and was discarded; all other positive fractions were subjected to phosphorylation assays with or without constitutively active AMPK221 and separated by SDS-PAGE (Fig. 3). Nine AMPK-specific bands could be identified in these interaction-positive fractions.

\subsection{Identification of candidate substrates of AMPK}

MALDI-MS/MS mass spectrometry of AMPK-specific phosphobands identified several proteins with significant MASCOTT score (Table 1, online Supplementary Material 2). Three of them are at least partially localized in the cytosol and are thus the most likely candidate substrates of AMPK in vivo. The $\gamma$-actin was already identified as a putative AMPK substrate in our earlier in vitro AMPK substrate screen [28]. Fumarate hydratase (FH) and fattyacid binding protein 1 (FABP1 or FABPL) are newly identified AMPK candidate substrates. FH occurs in identical form in mitochondria and cytosol, but has different functions in the two compartments [35]. FABP1, a small protein of $14.6 \mathrm{kDa}$, is the liver isoform of a family of nine different FABPs in mammals [36]. These proteins were analyzed for putative AMPK phosphorylation sites, either corresponding to the stringent consensus motif [31,37] or to recognition sequences identified by peptide library profiling [38]. While $\gamma$-actin did not contain a stringent AMPK site and was not further analyzed, FH preprotein and mature protein, as well as FABP1, contained at least one stringent AMPK site and additional less stringent sites.

\subsection{FH and FABP1 preferentially interact with AMPK $\alpha 2$}

We next wanted to confirm whether FH and FABP1 are indeed those proteins that were directly interacting with AMPK221 in the first dimension and phosphorylated by AMPK221 in the second dimension of our screen. A cytosolic yeast two-hybrid (Y2H) assay, the Cyto-Y2H [32,39], confirmed a direct protein-protein interaction in vivo between FH and the $\alpha 2$ and $\beta 2$ AMPK subunits, but not the $\alpha 1$ and $\beta 1$ subunits (Fig.4). Direct interaction of AMPK221 with FH could be confirmed by co-immunoprecipiation (Fig. 5). FABP1 showed the same specificity for $\alpha 2$, while it interacted only very weakly with both $\beta 1$ and $\beta 2$ (Fig. 4). These results confirm that $\mathrm{FH}$ and FABP1 are true interactors of AMPK. Importantly, they show specific interactions with the AMPK subunits used in the initial SPR screen: the AMPK $\alpha 2$ catalytic subunit (in case of $\mathrm{FH}$ and $\mathrm{FABP}$ ) and the $A M P K \beta 2$ regulatory subunit (in case of $\mathrm{FH}$ ). 

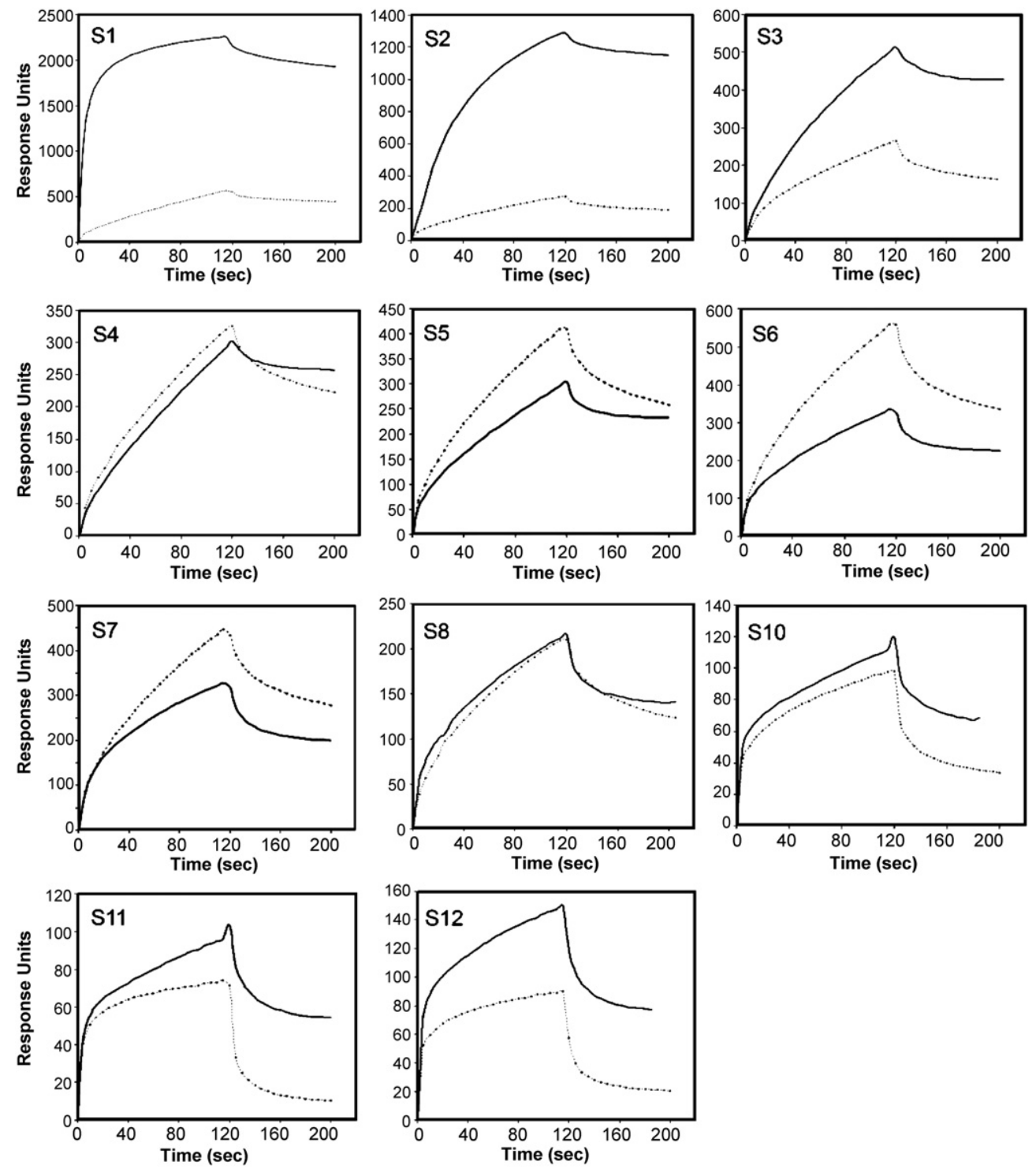

Fig. 2 - SPR interaction screening. Representative association/dissociation kinetics of different fractions from size exclusion chromatography injected onto immobilized AMPK221 (full lines) or empty surface (control, dotted lines).

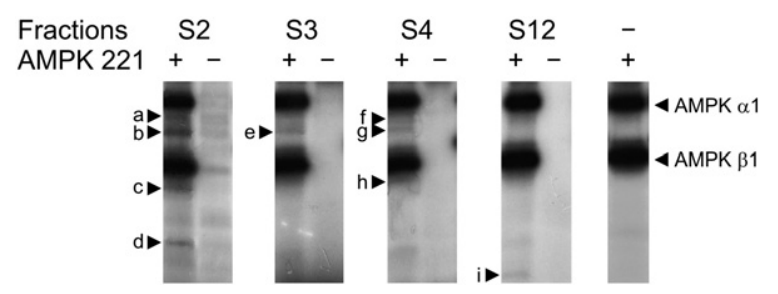

Fig. 3 - Phosphorylation assay screening. SPR positive fractions were subjected to in vitro phosphorylation assays with or without constitutively active $\alpha$ T172D AMPK221 using incubation with $\left[\gamma^{-32} \mathrm{P}\right] \mathrm{ATP}$ for $2 \mathrm{~min}$ at $37^{\circ} \mathrm{C}$. Assay mixtures analyzed by SDS-PAGE and Typhoon phospho-imager revealed AMPK auto-phosphorylation of $\alpha$ and $\beta$ subunits and phosphorylation of putative AMPK substrates (bands indicated by small letters). Phosphorylation patterns of fractions S10 and S11 were similar to S12 and are not shown.

\section{4. $\quad F H$ is directly phosphorylated by AMPK221}

Direct phosphorylation of FH and FABP1 by AMPK was verified by in vitro phosphorylation assays with purified recombinant proteins. In principle, phosphorylation in complex mixtures could also occur by another protein kinase which is itself activated by AMPK. FH and FABP1 were therefore expressed in E. coli as GSTand Strep-tagged proteins. GST-FH incorporated $\gamma^{-32} \mathrm{P}$ in presence of CamKK $\beta$-activated AMPK221 in a time-dependent manner (Fig. 6). Kinetics and extend of ${ }^{32} \mathrm{P}$ incorporation were comparable to the reference AMPK substrate acetyl-CoA carboxylase (ACC). Similar results were obtained with Strep-tagged FH (Suppl. Fig. 1), showing that $\mathrm{FH}$ phosphorylation was not due to an interaction of AMPK with the GST-tag (Klaus \& Schlattner, unpublished data). By contrast, FABP1 constructs were not phosphorylated under these conditions (not shown). Thus, the screen correctly identified $\mathrm{FH}$ as a true and direct substrate of AMPK in vitro. 
Table 1 - Protein identification by mass spectrometry.

\begin{tabular}{|c|c|c|c|c|c|c|c|c|}
\hline Fraction & Band & Identified protein & $\begin{array}{c}\text { Accession } \\
\text { no. }^{a}\end{array}$ & Score ${ }^{b}$ & $\begin{array}{l}\text { Mass } \\
(\mathrm{kDa})\end{array}$ & $\begin{array}{c}\text { No. } \\
\text { of peptides }\end{array}$ & Consensus sites ${ }^{c}$ & Subcellular localization \\
\hline \multirow[t]{3}{*}{ S2 } & a & ATP synthase subunit $\alpha$ & P15999 & 281 & 60 & 5 & Yes & Mitochondria \\
\hline & & Cytochrome P450 2D26 & P10634 & 150 & 57 & 3 & Yes & Mitochondria \\
\hline & $\mathrm{b}$ & 3-ketoacyl-CoA thiolase & P13437 & 210 & 41 & 6 & Yes & Mitochondria \\
\hline \multirow[t]{3}{*}{ S4 } & $\mathrm{f}$ & Aldehyde dehydrogenase & P11884 & 74 & 54 & 6 & Yes & Mitochondria \\
\hline & g & Fumarate hydratase & P14408 & 101 & 54 & 3 & Yes & $\begin{array}{l}\text { Cytosol and } \\
\text { mitochondria }\end{array}$ \\
\hline & & $\gamma$-actin & P63259 & 104 & 42 & 2 & No & Cytosol \\
\hline S12 & $\mathrm{i}$ & Fatty-acid-binding protein 1 & P02692 & 53 & 15 & 1 & Yes & Cytosol \\
\hline
\end{tabular}

Only vertebrate proteins identified with a significant MASCOTT score $(>50)$ and different from AMPK subunits are shown. Candidate substrates (highlighted in grey) were selected due to cytosolic localization and presence of stringent AMPK consensus phosphorylation motifs: $\phi(X, \beta) X X S /$ $\operatorname{TXXX} \phi$ ( $\phi$, hydrophobic residue; $\beta$, basic residue, [31]). ${ }^{a}$ UniProt accession number. ${ }^{b}$ Probability-based MOWSE scores greater than 50 were considered significant and not a random event. ${ }^{c}$ Presence of at least one stringent AMPK consensus site [31].

\section{5. $\quad F H$ is preferentially phosphorylated by $\alpha 2$-containing} AMPK complexes

We then wanted to know whether $\mathrm{FH}$ not only interacts specifically with AMPK221, but is also specifically phosphorylated by this AMPK isoform combination. Like above, in vitro phosphorylation assays were conducted with FH and ACC, using three different AMPK complexes: AMPK221, AMPK211, and AMPK111, all previously activated by CamKK $\beta$. ACC phosphorylation served to account for different specific activities of the AMPK complexes, since the ACC-derived SAMS peptide is an equally good substrate for $\alpha 1$ - and $\alpha 2$-containing AMPK complexes [27]. We first investigated the effect of different $\alpha$-subunits on $\mathrm{FH}$ phosphorylation (Fig. 7A). The ratio $\mathrm{P}-\mathrm{ACC}_{(221)} / \mathrm{P}-\mathrm{ACC}_{(111)}$ was 1,5 , while the ratio $\mathrm{P}-\mathrm{FH}_{(221)} / \mathrm{P}-\mathrm{FH}_{(111)}$ was 5,0. If normalized to ACC, FH is still 3,3 times more phosphorylated by $\mathrm{AMPK} \alpha 2$ as compared to $\mathrm{AMPK} \alpha 1$. Complexes containing different $\beta$ subunits (AMPK221 and AMPK211) phosphorylated both ACC and FH with similar efficiency (ratios of 1,1 for $\mathrm{P}-\mathrm{ACC}_{(221)} / \mathrm{P}-\mathrm{ACC}_{(211)}$ and 0.9 for $\mathrm{P}-\mathrm{FH}_{(221)} / \mathrm{P}-\mathrm{FH}_{(211)}$; Fig. 7B). Thus, at least in vitro, AMPK $\beta$-subunits have no effect on FH phosphorylation. These results strongly suggest that AMPK isoform composition can determine preference for specific substrates. FH interacts with AMPK $\alpha 2$ and is preferentially phosphorylated by $\alpha 2$-containing complexes. Although $\mathrm{FH}$ also interacts with the $\beta 2$-subunit, this does not affect phosphorylation efficiency.
3.6. FH phosphorylation by AMPK increases its enzyme activity in vitro and in vivo

We have finally addressed the effect of $\mathrm{FH}$ phosphorylation on its enzymatic function, which catalyzes the reversible hydratation/dehydration of fumarate to malate. Enzyme kinetics of FH were determined before and after in vitro phosphorylation by CamKK $\beta$-activated AMPK221, using malate as substrate and measuring fumarate formation by spectrophotometry. $\mathrm{FH}$ phosphorylation led to a $37 \%$ increase in $k_{\text {cat }}$ whereas the apparent $\mathrm{K}_{\mathrm{m}}$ remained almost unaffected (Fig. 8; Table 2). To investigate whether AMPK could also affect FH activity in vivo, we examined the effect of AMPK activation by its pharmacological agonist AICAR on FH activity in HeLa cells. Treatment of HeLa cells with $1 \mathrm{mM}$ AICAR for $1 \mathrm{~h}$ led to a strong increase in AMPK $\alpha$ Thr172 phosphorylation (Fig. 9A). This AMPK activation led to an average increase in $\mathrm{FH}$ activity by $31.3 \pm$ $6.4 \%$ (Fig. 9B). Similar results were obtained by activating AMPK with the Abbott compound A-769662 (not shown).

\section{Discussion}

The original two-dimensional in vitro screen for protein kinase substrates presented here combines biophysical interaction based on SPR with phosphorylation assays. Our data provide proof of principle that such a screening protocol can reveal

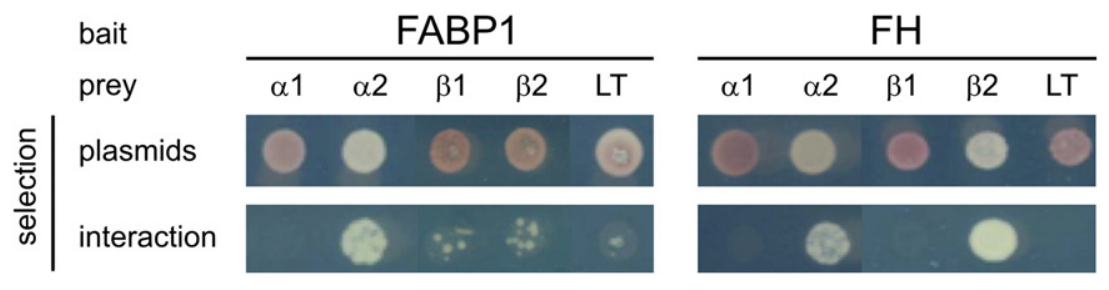

Fig. 4 - FABP1 and FH directly interact with specific AMPK subunits in Y2H analysis. Cytosolic Y2H analysis of interaction between the baits FABP1 or FH and the preys AMPK subunits $(\alpha 1, \alpha 2, \beta 1, \beta 2)$ or LT (Large T Antigen of Simian Virus, aa 84-704; negative control). Spots represent yeast grown for $72 \mathrm{~h}$ at $30^{\circ} \mathrm{C}(1 / 10$ dilution) either on medium selecting for the presence of bait and prey plasmids (upper row) and on medium selecting for bait/prey interaction (lower row). For more details see online Supplementary Material 1. 


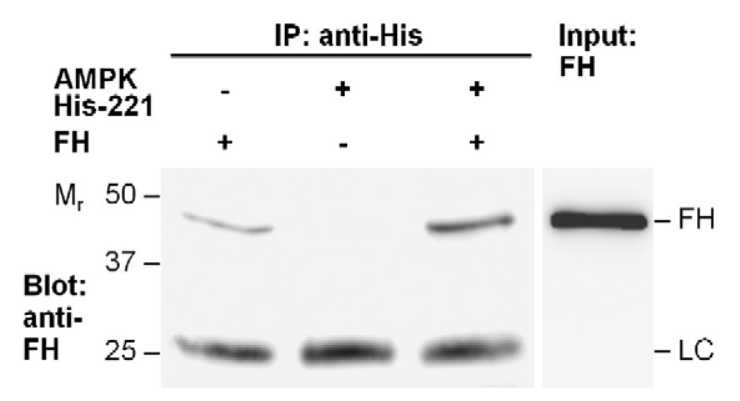

Fig. 5 - FH co-immunoprecipitates with AMPK221. Strep-tagged FH and His-tagged AMPK221 were immunoprecipitated by using anti-His antibodies, and FH detected by immunoblot analysis with anti-FH antibodies. LC, primary antibody IgG light chain.

AMPK substrates that are phosphorylated in an AMPK isoform-specific manner. We identified $\mathrm{FH}$ (or fumarase) as a novel AMPK substrate, and show that mainly the $\alpha 2$-subunit of AMPK is involved in FH interaction and recognition, as well as in FH phosphorylation. This phosphorylation increases $\mathrm{FH}$ enzymatic turnover in vitro and in vivo.

SPR technology has so far not been used to explore kinase/ substrate interaction for screening of novel kinase substrates. It has only been applied as high-throughput readout device to measure interactions between phosphorylated kinase substrates and anti-phospho antibodies [40]. High-thoughput procedures have also been developed to screen for AMPK activators or inhibitors (e.g. [41]). We show here that SPR can detect AMPK interactors in complex protein mixtures when different conditions are satisfied: (i) availability of highly pure, active kinase, as

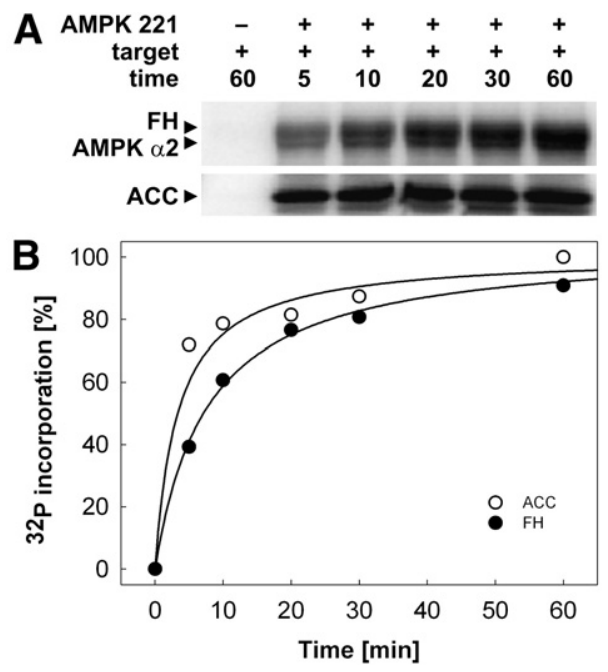

Fig. 6 - FH is a direct AMPK substrate. (A) Time course of FH phosphorylation by AMPK. AMPK221 (4 pmol) first activated by CamKK $\beta$ ( 1 pmol) was incubated with purified GST-FH (100 pmol) or GST-ACC (positive control, 100 pmol) for 5 to $60 \mathrm{~min}$ at $37^{\circ} \mathrm{C}$. In vitro phosphorylation assays were analyzed by SDS-PAGE and Typhoon phosphoimager. (B) Quantification of the phosphorylation time course using Image Quant TL. Data is normalized to maximal ACC phosphorylation. Symbols: GST-ACC (०), GST-FH (•).
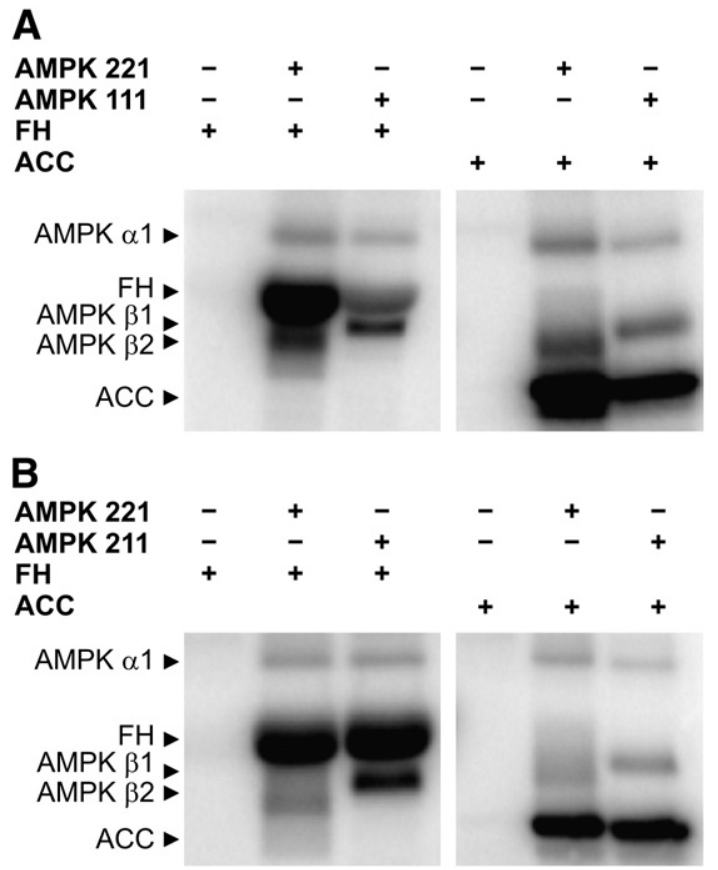

Fig. 7 - AMPK isoform composition affects FH phosphorylation. (A) AMPK221 phosphorylates FH more efficiently than AMPK111. (B) AMPK221 and AMPK211 phosphorylate FH and ACC with similar efficiency. Conditions: 3 pmol AMPK221, -211 or -111 first activated by CamKK $\beta$ (1 pmol) were incubated with purified FH or ACC (200 pmol) for $8 \mathrm{~min}$ at $37^{\circ} \mathrm{C}$. In vitro phosphorylation assays were analyzed by SDS-PAGE and Typhoon phosphoimager.

we have established by polycistronic bacterial expression of full-length AMPK complex [29]; (ii) reversible, high density immobilization of the kinase on the chip surface for repeated use with fresh protein (e.g. by using Ni-NTA); (iii) the use of prefractionated extracts as source of soluble protein to reduce

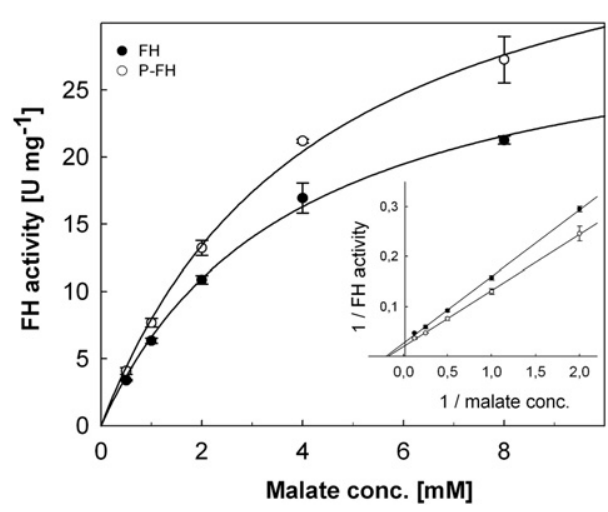

Fig. 8 - AMPK-mediated phosphorylation affects enzymatic catalysis of FH. Enzyme activity of phosphorylated (0) and non-phosphorylated ( $\bullet$ FH at different concentrations of malate, measured as described in material and methods. The direct fit to original data (large graph) and Lineweaver-Burk plot (insert graph) are shown. The derived catalytic constants are given in Table 2. 
Table 2 - Phosphorylation by AMPK activates FH. Enzyme kinetic parameters of recombinant FH before and after phosphorylation with AMPK221 activated by CamKK $\beta$.

\begin{tabular}{lcccc} 
& $\begin{array}{c}\mathrm{V}_{\text {max }} \\
\left(\mathrm{U} \mathrm{mg} \mathrm{mg}^{-1}\right)\end{array}$ & $\begin{array}{c}\mathrm{k}_{\mathrm{cat}} \\
\left(\mathrm{s}^{-1}\right)\end{array}$ & $\begin{array}{c}\mathrm{K}_{\mathrm{m} \text { (malate) }} \\
(\mathrm{mM})\end{array}$ & $\begin{array}{c}\mathrm{k}_{\mathrm{cat}} / \mathrm{K}_{\mathrm{m}} \\
\left(\mathrm{mM}^{-1} \mathrm{~s}^{-1}\right)\end{array}$ \\
\hline FH & $32,9 \pm 0,4$ & $110,0 \pm 1,3$ & $4,2 \pm 0,1$ & 26,2 \\
P-FH & $45,1 \pm 1,4$ & $150,8 \pm 4,7$ & $4,6 \pm 0,3$ & 32,8
\end{tabular}

Measurements with variable concentrations of malate at $25^{\circ} \mathrm{C}$ (see Fig. 8). Enzyme activity is given in $\mathrm{U}$, equivalent to $1 \mu \mathrm{mol} / \mathrm{min}$. Catalytic efficiency is calculated as $\mathrm{k}_{\mathrm{cat}} / \mathrm{K}_{\mathrm{m}}$. Results are given as means $\pm S E(n=2)$ of two independent phosphorylation experiments.

complexity; and in particular (iv) prior removal of proteins with non-specific affinity to the chip surface (especially relevant for Ni-NTA). We have assembled these conditions in a protocol (Fig. 1) that provides useful data for AMPK and soluble liver proteins. The resolving power of the screen could be further improved by using multidimensional prefractionation (e.g. by additional ion exchange chromatography) or detection approaches (e.g. 2D-PAGE of interaction-positive fractions).

From SPR-positive fractions, FH and FABP1 were identified as direct AMPK221-interacting proteins. Another FABP family member, the epidermal FABP5, and FH were also part of AMPKcontaining complexes in an earlier large-scale anti-bait coimmunoprecipitation study using AMPK- $\beta 1$ [24]. However, here we show that both proteins exclusively interact with subunits used in our SPR screen: the $\alpha 2$ - and (in case of FH) the $\beta 2$ subunits. In addition, recombinant FH, but not FABP1, was also phosphorylated by AMPK in vitro. Possibly, FABP1 phosphorylation by AMPK requires additional factors (i.e. fatty acids) or secondary modifications missing in the bacterially expressed FABP1 but present in endogenous liver protein. Phosphorylation of FH constructs by AMPK221 occurred with kinetics and a degree of ${ }^{32} \mathrm{P}$-incorporation per mol of protein that were similar to the well characterized AMPK substrate ACC. Like for FH/AMPK interaction, $\mathrm{FH}$ was phosphorylated predominantly by complexes containing the $\alpha 2$-subunit as compared to $\alpha 1$-complexes. This is one of the first reports showing a clear preference of mammalian AMPK complexes for one of its substrates [27]. Such substrate specificity may contribute to tissue- and compartment-specific AMPK signaling whose mechanisms are so far largely unsolved.

$\mathrm{FH}$ or fumarase is encoded by a single gene, but dualtargeted to mitochondria and cytosol (reviewed in [35]). As studied in yeast, after cleavage of the signal peptide in mitochondria, identical mature $\mathrm{FH}$ variants relocate in a metabolically regulated process either to the mitochondrial matrix or to the cytosol. In humans or yeast, cytosolic FH (cFH) represents about half of the cellular FH pool and is the likely substrate of AMPK in vivo [35]. While mitochondrial FH is well known for its participation in the tricarboxylic acid cycle (TCC), converting fumarate into malate, the role of $\mathrm{cFH}$ is emerging only more recently. Recent research is driven by the tumor suppressor function of $\mathrm{FH}$ which suggests that metabolic signals can regulate carcinogenesis (reviewed in [42]). Cancer incidence is linked to $\mathrm{cFH}$ inhibition and/or the resulting cytosolic fumarate accumulation, which may act via different mechanisms. These include induction of pseudohypoxia via stabilization of HIF-1 $\alpha$ [43], signaling via serum responsive factor [44], up-regulation of antioxidant-response element-
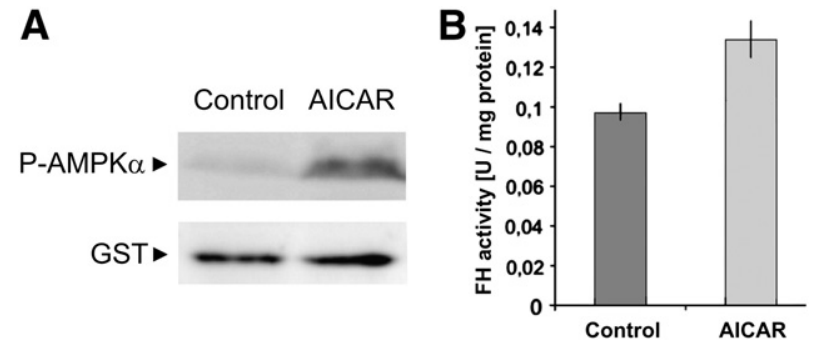

Fig. 9 - Pharmacological AMPK activation increases FH enzyme activity in HeLa cells. (A) Treatment of HeLa cells with $1 \mathrm{mM}$ AICAR for $1 \mathrm{~h}$ increases AMPK activity as shown by immunoblotting for P- $\alpha$ Thr172 AMPK with glutathione S-transferase pi (GST) as loading control. (B) FH activity in HeLa cells increases after AMPK activation as measured spectrophotometrically using malate as substrate (for details see material and methods). One representative experiment of three independent activation experiments is shown.

controlled genes $[45,46]$, or inhibition of DNA damage response [47]. In the latter mechanism, cellular stressors leading to DNA damage, induce $\mathrm{cFH}$ translocation to the nucleus, where its enzymatic activity is required to activate the DNA repair machinery, thus avoiding genomic instability. Our study together with literature data suggest that phosphorylation and activation of $\mathrm{cFH}$ by AMPK could play an important role in this sequence of events. AMPK signaling is known to respond to DNA damage and genotoxic stress transmitted via p53 and the p53 targets Sestrin1 and Sestrin2 [48] or the cellular damage sensor ataxia-telangiectasia mutated protein (ATM) [49]. Furthermore, the nuclear functions of AMPK are mediated by $\alpha 2-$ complexes ( $\alpha 1$-complexes are not localizing to the nucleus) [50], exactly the isoform that preferentially phosphorylates $\mathrm{CFH}$.

In summary, we provide proof of concept that combining classical in vitro AMPK phosphorylation assays with SPRbased AMPK-protein interaction screening can not only identify novel AMPK substrates but also enrich for AMPK isoform-specific substrates. The newly identified AMPK substrate $\mathrm{FH}$ is exclusively interacting with and preferentially phosphorylated by $\alpha 2$-containing AMPK complexes. Both phosphorylation and activation of FH could contribute to the tumor suppressor function of $\mathrm{FH}$.

Supplementary data to this article can be found online at doi:10.1016/j.jprot.2012.03.040.

\section{Acknowledgements}

This work was supported by EU FP6 contract LSHM-CT-2004005272 (EXGENESIS), the French Fondation pour la Recherche Médicale (to A. Klaus, nee Brückner) and the French Agence Nationale de Recherche ("chaire d'excellence" to U.S.). We thank Daniel Auerbach (Dualsystems Schlieren, Switzerland) for providing an unpublished version of the Cyto-Y2H system, and Grahame Hardie (University of Dundee) and H. Tokumitsu (Kagawa Medical University) for providing GST-ACC and CamKK $\beta$ expression vectors. The abbreviations used are: ACC, acetyl-CoA carboxylase; AICAR, aminoimidazole carboxamide ribonucleotide; AMPK, AMP-activated protein kinase; CaMKK, 
$\mathrm{Ca}^{2+} /$ calmodulin-dependent protein kinase kinase; FABP, fatty acid binding protein; $\mathrm{FH}$, fumarate hydratase; $\mathrm{CFH}$, cytosolic $\mathrm{FH}$; MS, mass spectrometry; Ni-NTA, nickel-nitrilotriacetic acid; SPR, surface plasmon resonance; TCC, tricarboxylic acid cycle; Y2H, yeast two-hybrid.

\section{R E F E R E N C E S}

[1] Bouly JP, Gissot L, Lessard P, Kreis M, Thomas M. Arabidopsis thaliana proteins related to the yeast SIP and SNF4 interact with AKINalpha1, an SNF1-like protein kinase. Plant J 1999;18: 541-50.

[2] Davies SP, Hawley SA, Woods A, Carling D, Haystead TA, Hardie DG. Purification of the AMP-activated protein kinase on ATP-gamma-sepharose and analysis of its subunit structure. Eur J Biochem 1994;223:351-7.

[3] Mitchelhill KI, Stapleton D, Gao G, House C, Michell B, Katsis F, et al. Mammalian AMP-activated protein kinase shares structural and functional homology with the catalytic domain of yeast Snf1 protein kinase. J Biol Chem 1994;269: 2361-4.

[4] Jiang R, Carlson M. The Snf1 protein kinase and its activating subunit, Snf4, interact with distinct domains of the Sip1/Sip2/Gal83 component in the kinase complex. Mol Cell Biol 1997;17:2099-106.

[5] Hardie DG. AMP-activated/SNF1 protein kinases: conserved guardians of cellular energy. Nat Rev Mol Cell Biol 2007;8: 774-85.

[6] Neumann D, Schlattner U, Wallimann T. A molecular approach to the concerted action of kinases involved in energy homoeostasis. Biochem Soc Trans 2003;31:169-74.

[7] Carling D, Mayer FV, Sanders MJ, Gamblin SJ. AMP-activated protein kinase: nature's energy sensor. Nat Chem Biol 2011;7: 512-8.

[8] Mihaylova MM, Shaw RJ. The AMPK signalling pathway coordinates cell growth, autophagy and metabolism. Nat Cell Biol 2011;13:1016-23.

[9] Riek U, Scholz R, Konarev P, Rufer A, Suter M, Nazabal A, et al. Structural properties of AMP-activated protein kinase: dimerization, molecular shape, and changes upon ligand binding. J Biol Chem 2008;283:18331-43.

[10] Woods A, Johnstone SR, Dickerson K, Leiper FC, Fryer LG, Neumann D, et al. LKB1 is the upstream kinase in the AMP-activated protein kinase cascade. Curr Biol 2003;13: 2004-8.

[11] Fogarty S, Hardie DG. Development of protein kinase activators: AMPK as a target in metabolic disorders and cancer. Biochim Biophys Acta 2010;1804:581-91.

[12] Steinberg GR, Kemp BE. AMPK in Health and Disease. Physiol Rev 2009;89:1025-78.

[13] Fryer LG, Parbu-Patel A, Carling D. The Anti-diabetic drugs rosiglitazone and metformin stimulate AMP-activated protein kinase through distinct signaling pathways. J Biol Chem 2002;277:25226-32.

[14] Zhou G, Myers R, Li Y, Chen Y, Shen X, Fenyk-Melody J, et al. Role of AMP-activated protein kinase in mechanism of metformin action. J Clin Invest 2001;108:1167-74.

[15] Shaw RJ, Lamia KA, Vasquez D, Koo SH, Bardeesy N, Depinho RA, et al. The kinase LKB1 mediates glucose homeostasis in liver and therapeutic effects of metformin. Science 2005;310:1642-6.

[16] Libby G, Donnelly LA, Donnan PT, Alessi DR, Morris AD, Evans JM. New users of metformin are at low risk of incident cancer: a cohort study among people with type 2 diabetes. Diabetes Care 2009;32:1620-5.
[17] Alessi DR, Sakamoto K, Bayascas JR. LKB1-dependent signaling pathways. Annu Rev Biochem 2006;75:137-63.

[18] Jones RG, Plas DR, Kubek S, Buzzai M, Mu J, Xu Y, et al. AMP-activated protein kinase induces a p53-dependent metabolic checkpoint. Mol Cell 2005;18:283-93.

[19] Kimura N, Tokunaga C, Dalal S, Richardson C, Yoshino K, Hara K, et al. A possible linkage between AMP-activated protein kinase (AMPK) and mammalian target of rapamycin (mTOR) signalling pathway. Genes Cells 2003;8:65-79.

[20] Viollet B, Lantier L, Devin-Leclerc J, Hebrard S, Amouyal C, Mounier R, et al. Targeting the AMPK pathway for the treatment of Type 2 diabetes. Front Biosci 2009;14:3380-400.

[21] Vincent O, Carlson M. Gal83 mediates the interaction of the Snf1 kinase complex with the transcription activator Sip4. EMBO J 1999;18:6672-81.

[22] Polge C, Jossier M, Crozet P, Gissot L, Thomas M. Betasubunits of the SnRK1 complexes share a common ancestral function together with expression and function specificities; physical interaction with nitrate reductase specifically occurs via AKINbeta1-subunit. Plant Physiol 2008;148:1570-82.

[23] Woods A, Salt I, Scott J, Hardie DG, Carling D. The alpha1 and alpha2 isoforms of the AMP-activated protein kinase have similar activities in rat liver but exhibit differences in substrate specificity in vitro. FEBS Lett 1996;397:347-51.

[24] Ewing RM, Chu P, Elisma F, Li H, Taylor P, Climie S, et al. Large-scale mapping of human protein-protein interactions by mass spectrometry. Mol Syst Biol 2007;3:89.

[25] Kuramoto N, Wilkins ME, Fairfax BP, Revilla-Sanchez R, Terunuma M, Tamaki K, et al. Phospho-dependent functional modulation of GABA(B) receptors by the metabolic sensor AMP-dependent protein kinase. Neuron 2007;53:233-47.

[26] Solaz-Fuster MC, Gimeno-Alcaniz JV, Casado M, Sanz P. TRIP6 transcriptional co-activator is a novel substrate of AMP-activated protein kinase. Cell Signal 2006;18:1702-12.

[27] Vernia S, Solaz-Fuster MC, Gimeno-Alcaniz JV, Rubio T, Garcia-Haro L, Foretz M, et al. AMP-activated protein kinase phosphorylates R5/PTG, the glycogen targeting subunit of the R5/PTG-protein phosphatase 1 holoenzyme, and accelerates its down-regulation by the laforin-malin complex. J Biol Chem 2009;284:8247-55.

[28] Tuerk RD, Thali RF, Auchli Y, Rechsteiner H, Brunisholz RA, Schlattner U, et al. New candidate targets of AMP-activated protein kinase in murine brain revealed by a novel multidimensional substrate-screen for protein kinases. J Proteome Res 2007;6:3266-77.

[29] Neumann D, Woods A, Carling D, Wallimann T, Schlattner U. Mammalian AMP-activated protein kinase: functional, heterotrimeric complexes by co-expression of subunits in Escherichia coli. Protein Expr Purif 2003;30:230-7.

[30] Riek U, Ramirez S, Wallimann T, Schlattner U. A versatile multidimensional protein purification system with full internet remote control based on a standard HPLC system. Biotechniques 2009;46:ix-xii.

[31] Scott JW, Norman DG, Hawley SA, Kontogiannis L, Hardie DG. Protein kinase substrate recognition studied using the recombinant catalytic domain of AMP-activated protein kinase and a model substrate. J Mol Biol 2002;317:309-23.

[32] Mockli N, Deplazes A, Hassa PO, Zhang Z, Peter M, Hottiger MO, et al. Yeast split-ubiquitin-based cytosolic screening system to detect interactions between transcriptionally active proteins. Biotechniques 2007;42:725-30.

[33] Johnsson N, Varshavsky A. Split ubiquitin as a sensor of protein interactions in vivo. Proc Natl Acad Sci U S A 1994;91:10340-4.

[34] Stagljar I, Korostensky C, Johnsson N, te Heesen S. A genetic system based on split-ubiquitin for the analysis of interactions between membrane proteins in vivo. Proc Natl Acad Sci U S A 1998;95:5187-92. 
[35] Yogev O, Naamati A, Pines O. Fumarase: a paradigm of dual targeting and dual localized functions. FEBS J 2011;278: 4230-42.

[36] Storch J, Corsico B. The emerging functions and mechanisms of mammalian fatty acid-binding proteins. Annu Rev Nutr 2008;28:73-95.

[37] Scott JW, Norman DG, Hawley SA, Kontogiannis L, Hardie DG. Protein kinase substrate recognition studied using the recombinant catalytic domain of AMP-activated protein kinase and a model substrate. J Mol Biol 2002;317:309-23.

[38] Gwinn DM, Shackelford DB, Egan DF, Mihaylova MM, Mery A, Vasquez DS, et al. AMPK phosphorylation of raptor mediates a metabolic checkpoint. Mol Cell 2008;30:214-26.

[39] Bruckner A, Polge C, Lentze N, Auerbach D, Schlattner U. Yeast two-hybrid, a powerful tool for systems biology. Int $J$ Mol Sci 2009;10:2763-88.

[40] Takeda H, Goshima N, Nomura N. High-throughput kinase assay based on surface plasmon resonance. Methods Mol Biol 2010;627:131-45.

[41] Anderson SN, Cool BL, Kifle L, Chiou W, Egan DA, Barrett LW. Microarrayed compound screening (microARCS) to identify activators and inhibitors of AMP-activated protein kinase. J Biomol Screen 2004;9:112-21.

[42] Raimundo N, Baysal BE, Shadel GS. Revisiting the TCA cycle: signaling to tumor formation. Trends Mol Med 2011;17:641-9.

[43] O'Flaherty L, Adam J, Heather LC, Zhdanov AV, Chung YL, Miranda MX, et al. Dysregulation of hypoxia pathways in fumarate hydratase-deficient cells is independent of defective mitochondrial metabolism. Hum Mol Genet 2010;19:3844-51.
[44] Raimundo N, Vanharanta S, Aaltonen LA, Hovatta I, Suomalainen A. Downregulation of SRF-FOS-JUNB pathway in fumarate hydratase deficiency and in uterine leiomyomas. Oncogene 2009;28:1261-73.

[45] Ooi A, Wong JC, Petillo D, Roossien D, Perrier-Trudova V, Whitten $\mathrm{D}$, et al. An antioxidant response phenotype shared between hereditary and sporadic type 2 papillary renal cell carcinoma. Cancer Cell 2011;20:511-23.

[46] Tong WH, Sourbier C, Kovtunovych G, Jeong SY, Vira M, Ghosh $\mathrm{M}$, et al. The glycolytic shift in fumarate-hydratase-deficient kidney cancer lowers AMPK levels, increases anabolic propensities and lowers cellular iron levels. Cancer Cell 2011;20:315-27.

[47] Yogev O, Singer E, Shaulian E, Goldberg M, Fox TD, Pines O. Fumarase: a mitochondrial metabolic enzyme and a cytosolic/nuclear component of the DNA damage response. PLoS Biol 2010;8:e1000328.

[48] Budanov AV, Karin M. p53 target genes sestrin1 and sestrin2 connect genotoxic stress and mTOR signaling. Cell 2008;134: 451-60.

[49] Alexander A, Cai SL, Kim J, Nanez A, Sahin M, MacLean KH, et al. ATM signals to TSC2 in the cytoplasm to regulate mTORC1 in response to ROS. Proc Natl Acad Sci U S A 2010;107:4153-8.

[50] Salt I, Celler JW, Hawley SA, Prescott A, Woods A, Carling D, et al. AMP-activated protein kinase: greater AMP dependence, and preferential nuclear localization, of complexes containing the alpha2 isoform. Biochem J 1998;334(Pt 1): 177-87. 